\title{
RELAÇÕES ENTRE O DISCURSO DO PROFESSOR E A ARGUMENTAÇÃO DOS ALUNOS EM UMA AULA DE FÍSICA
}

\author{
Maria Cândida Varone de Morais Capecchi \\ Anna Maria Pessoa de Carvalho \\ Dirceu da Silva
}

\begin{abstract}
Resumo
O presente trabalho é voltado para o estudo das interações discursivas que propiciam a argumentação dos alunos em aulas de Física - compreendendo a identificação tanto de componentes de seus argumentos, quanto de padrões discursivos determinados pelas intervenções do professor. São analisadas duas cenas dentro de um episódio de ensino extraído de uma seqüência de aulas relacionadas ao estudo do funcionamento do microondas, realizadas com alunos do primeiro ano do ensino médio. Nas duas cenas, os argumentos empregados pelos alunos contaram com refutações e também com a formulação de uma síntese das principais idéias discutidas. Este resultado foi atribuído tanto à apresentação de conhecimentos básicos por parte dos mesmos, quanto à alternância de padrões discursivos empregados pelo professor.
\end{abstract}

\section{Abstract \\ STUDENTS' ARGUMENTATION IN THE PHYSICS CLASSROOM AND IT'S RELATIONSHIP WITH THE TEACHER SPEECH}

This work is directed to the discursive interactions, which propitiate the students', argumentation in the Physics classes - understanding the arguments components identification and the discursive patterns determined by teachers' interventions. Two scenes in a teaching episode extracted from a High School classes sequence related to the microwave oven working are analysed. On the two scenes, there were arguments refutations and the mains discussed ideas had a synthesis formulated. This result was attributed to the students' basic knowledge and the discursive patterns used by the teacher. 


\section{Introdução}

As pesquisas em ensino de ciências têm evoluído de uma abordagem psicológica, mais voltada aos aspectos individuais da construção do conhecimento, para uma abordagem sociológica, em que tal construção é considerada dentro de contextos sociais (Duit e Treagust, 1998; Cobern e Aikenhead, 1998). Enquanto no construtivismo tradicional o enfoque principal das pesquisas era o desenvolvimento de atividades de ensino que pudessem gerar conflitos cognitivos nos indivíduos, numa análise sob perspectiva social, ganham uma maior atenção o contextos em que tais conflitos são gerados e a forma como explicações são construídas e compartilhadas entre estudantes em sala de aula.

Os modelos visando mudança conceitual, por exemplo, que no final dos anos setenta e início dos oitenta estavam voltados para a extinção e substituição das concepções préinstrucionais por aquelas corretas do ponto de vista científico (Duit e Treagust, 1998), têm caminhado para a criação de meios que proporcionem a construção de explicações contextualizadas por parte dos alunos. Neste caso, ao invés de uma tentativa de substituição de concepções, passa-se para a busca de uma convivência entre as mesmas, em que o sujeito tem a consciência da adequação de cada uma a situações específicas. Esta mudança de enfoque acrescenta novos fatores aos estudos sobre aprendizagem, dentre eles a linguagem utilizada em sala de aula.

Cobern e Aikenhead (1998) chamam a atenção para a crescente influência que a abordagem antropológica vem exercendo nas pesquisas em ensino e aprendizagem de ciências, oferecendo novas interpretações para as mesmas. A concepção da ciência como uma espécie de cultura nos permite contemplar características importantes do conhecimento científico, tais como, sua construção e sua validação sociais e os termos específicos que compõem a linguagem científica. Desta forma, a aprendizagem de ciências pode ser considerada como uma espécie de enculturação, em que o estudante entra em contato com uma nova forma de ver os fenômenos e uma linguagem específica para explicá-los (Driver e Newton, 1997).

Porém, é importante que esta enculturação não seja considerada como uma mera aquisição das característica de uma nova cultura em detrimento da cultura pré existente, formada no cotidiano. Para evitar tal interpretação, Cobern e Aikenhead (1998) denominaram enculturação autônoma aquela em que o estudante transpõe as fronteiras entre sua cultura cotidiana e a cultura científica e aprende a utilizar-se das vantagens de cada uma em contextos específicos, ou seja, o estudante passa a apreciar o potencial das explicações científicas e saber como utilizá-las dentro dos contextos adequados, sem anular toda sua experiência anterior.

Partindo de uma concepção de aprendizagem como enculturação autônoma, acreditamos que o espaço para a fala dos alunos e, mais especificamente, para a argumentação em sala de aula seja fundamental. Através da oportunidade de ensaiar o uso de uma nova linguagem, que carrega consigo características da cultura científica, o estudante pode ir adquirindo desenvoltura dentro da mesma, bem como experimentar e ponderar as vantagens de sua utilização em contextos adequados (Driver e Newton, 1997). 
Sutton (1998) chama a atenção para a importância da conscientização dos alunos sobre o papel da linguagem em suas próprias aprendizagens: "Aprendizes deveriam experimentar a linguagem como um meio para a conversação sobre idéias, não apenas para receber a 'verdade'. Estudantes deveriam re - trabalhar idéias científicas e praticar o uso das mesmas em argumentos e decisões". Para que possam compreender o papel da linguagem científica, é necessário que os estudantes tenham a oportunidade de experimentar seu uso na elaboração de explicações em sala de aula.

Um grande obstáculo para o desenvolvimento de tarefas que proporcionem discussões em sala de aula, é a dificuldade do professor em organizá-las, desde a administração da gradativa adaptação dos alunos ao processo de ouvir os colegas, até o direcionamento de suas questões para uma sistematização de idéias, que leve a conclusões. Portanto, 0 acompanhamento da forma com que os professores administram o processo, como intervêm com o intuito de dar suporte à fala dos alunos durante o trabalho com atividades envolvendo argumentação, é essencial para que seu desenvolvimento seja possível.

O estudo apresentado neste artigo está inserido dentro de uma pesquisa sobre a argumentação em sala de aula como meio de favorecimento da aprendizagem, tendo sido realizado com o objetivo de identificar os argumentos empregados pelos alunos, assim como as contribuições do professor para a formulação dos mesmos.

\section{Investigações sobre argumentação em aulas de Ciências}

A argumentação nas aulas de Ciências tem sido investigada sob diferentes enfoques (Kuhn, 1993; Richmond e Striley, 1996; Candela,1997; Driver e Newton, 1997; JiménezAleixandre, 1998).

Candela (1997), observou que à medida em que práticas discursivas são incentivadas nas aulas de ciências, os alunos vão se apropriando de novas formas de se expressar, adquirindo mais independência e confiança em suas idéias, além de atitudes mais científicas baseadas na atuação do professor. A autora procurou identificar características do discurso argumentativo na sala de aula. A criação de situações de conflito foi apontada como uma forma de envolver os alunos na busca de recursos discursivos para a validação de suas versões sobre conteúdos de ciências.

Richmond e Striley (1996) realizaram um estudo mostrando que determinadas ações inerentes ao estudo de ciências - identificação de um problema, elaboração de hipóteses testáveis, coleta e síntese de dados e discussão do significado dos mesmos - denominadas por eles habilidades de argumentação dos estudantes, podem evoluir a partir de programas de atividades adequados a este fim. Os autores observaram que a evolução das habilidades de argumentação depende do estilo de liderança dentro dos grupos de alunos. O maior rendimento foi observado nos grupos cujos líderes incentivavam a distribuição de trabalho entre todos os membros, assim como a contribuição de todos na construção de argumentos, ou seja, observou-se a importância de uma postura cooperativa por parte dos alunos.

Dentro de uma perspectiva de aprendizagem como enculturação, Driver e Newton (1997) apontaram o papel que a argumentação entre os alunos pode representar na aprendizagem de ciências, tanto do ponto de vista conceitual, a partir do domínio da linguagem científica, quanto 
do ponto de vista epistemológico, compreendendo sua construção social. Para tanto, além de sugerirem a criação de atividades estimulantes para que os alunos argumentem em sala de aula, os autores elaboraram categorias de análise a partir de um padrão de argumento desenvolvido por Toulmin (1958).

Jiménez Aleixandre et al. (1998), realizaram uma pesquisa em que identificaram detalhadamente os tipos de argumentos utilizados pelos alunos - dados, conclusões, justificativas, conhecimentos básicos, qualificadores, refutações ou oposições simples também a partir do modelo desenvolvido por Toulmin. Acreditando que a capacidade de argumentar está relacionada com o tipo de instrução e com as situações de aprendizagem, os autores realizaram a análise das discussões de estudantes do ensino médio enquanto resolviam problemas experimentais de física. A partir da identificação dos principais tipos de argumentos utilizados pelos alunos foi possível avaliar qual a atenção que estes dispensaram aos dados experimentais e de que forma as teorias estudadas auxiliaram em suas reflexões. As conclusões deste estudo mostraram o emprego de argumentos de qualidade pouco elevada, com pouco uso de justificativas e de conhecimentos básicos, porém foi observado que atividades envolvendo problemas abertos são adequadas para gerar ambientes de discussão.

\section{Referenciais Teóricos para a Análise do Episódio de Ensino}

Considerando o objetivo de investigar os argumentos construídos pelos alunos, assim como as contribuições do professor, a análise dos dados foi realizada a partir de duas perspectivas: uma mais geral, abrangendo as interações discursivas professor - alunos, e outra mais específica, voltada para a identificação dos argumentos dos alunos. Para tanto, foram empregados diferentes referenciais teóricos. A investigação das interações discursivas foi inspirada no trabalho de Mortimer e Machado (1997), em que padrões discursivos IRF foram identificados numa aula de química. Os argumentos construídos pelos alunos foram identificados e classificados a partir de um padrão desenvolvido por Toulmin (1958) e uma variante do mesmo proposta por Driver e Newton (1997).

\subsection{Propostas de análise de argumentação baseadas no modelo de Toulmin}

Toulmin (1958) desenvolveu um padrão para a análise de argumentos que identifica, além dos elementos básicos que os compõem, as relações entre estes elementos.

Os elementos fundamentais de um argumento segundo o padrão acima são o dado, a conclusão e a justificativa. É possível apresentar um argumento contando apenas com estes elementos, cuja estrutura básica é: "a partir de um dado D, já que J, então C". Porém, para que um argumento seja completo pode-se especificar em que condições a justificativa apresentada é valida ou não, indicando um 'peso' para tal justificativa. Desta forma podem ser acrescentados ao argumento qualificadores modais (Q), ou seja, especificações das condições necessárias para que uma dada justificativa seja válida. Da mesma forma, é possível especificar em que condições a justificativa não é válida ou suficiente para dar suporte à conclusão. Neste caso é apresentada uma refutação $(R)$ da justificativa. Os qualificadores e as 
refutações dão os limites de atuação de uma determinada justificativa, complementando a 'ponte' entre dado e conclusão.

Além dos elementos citados acima, a justificativa, que apresenta um caráter hipotético, pode ser apoiada em uma alegação categórica baseada em uma lei, por exemplo. Trata-se de uma alegação que dá suporte à justificativa, denominada "backing" (B) ou conhecimento básico. O "backing" é uma garantia baseada em alguma autoridade, uma lei jurídica ou científica, por exemplo, que fundamenta a justificativa.

O modelo de Toulmin é uma ferramenta importante para a compreensão da argumentação no pensamento científico. Além de mostrar o papel das evidências na elaboração de afirmações, relacionando dados e conclusões através de justificativas de caráter hipotético, também realça as limitações de uma dada teoria, bem como sua sustentação em outras teorias. O uso de qualificadores ou de refutações envolve a capacidade de ponderar diante de diferentes teorias a partir das evidências apresentadas por cada uma delas. Um modelo, por exemplo, pode ser útil para uma situação específica, porém substituído por outro mais abrangente em outras circunstâncias. Ao participar de discussões envolvendo argumentos completos, os alunos podem entrar em contato com uma importante faceta do conhecimento científico.

Ao lado das qualidades citadas acima, como apontado por Driver e Newton (1997), tal modelo também apresenta importantes limitações, tais como, a desconsideração do contexto em que os argumentos são construídos e a falta de julgamento da precisão dos mesmos. Além disso, um aspecto fundamental das explicações científicas não é contemplado - sua construção coletiva. Os argumentos nem sempre aparecem de forma ordenada como indicado no modelo, justificativas podem estar implícitas e falas de diferentes alunos podem ser complementares.

Considerando que uma mesma afirmação pode ter diferentes significados em diferentes contextos, em nossa análise procuramos classificar como conhecimentos básicos todas as referências a conhecimentos já compartilhados pelos alunos ao longo da escolarização. A suficiência de uma afirmação depende mais do momento em que é utilizada dentro de uma seqüência de ensino, do que de sua correção do ponto de vista científico.

Para evitar uma análise rígida e descontextualizada dos argumentos, procuramos observar a conexão entre afirmações complementares citadas por diferentes participantes. $O$ padrão de Toulmin foi empregado como um guia para a identificação de alguns elementos importantes dos argumentos individuais, visando, porém, o objetivo maior de acompanhar a construção coletiva de argumentos mais completos por parte de todo o grupo de alunos.

\subsubsection{Categorias desenvolvidas por Driver e Newton}

Além de identificarmos os componentes dos argumentos dos alunos através do padrão de Toulmin, também nos inspiramos em algumas categorias desenvolvidas por Driver e Newton (1997) a partir do mesmo padrão. Tais categorias foram criadas dentro de uma proposta de desenvolvimento da argumentação em sala de aula visando uma aculturação em ciências, compreendendo entre outros a construção coletiva do conhecimento científico.

Com base na preocupação fundamental de promover um entendimento da ciência como produto de uma construção coletiva, tais categorias valorizam a presença de teorias conflitantes 
e as sínteses nas discussões em sala de aula. Assim, a cada categoria é atribuído um nível de qualidade com base na complexidade dos argumentos utilizados, assim como na interação entre diferentes idéias. O uso de qualificadores ou refutações (nível 3) só é necessário quando há afirmações competindo (nível 2); um argumento que não sofre nenhum questionamento pode ser incompleto, contando ou não com uma justificativa (níveis 1 e 0 , respectivamente). Fazer julgamento integrando diferentes argumentos (nível 4) indica uma boa compreensão dos conceitos envolvidos. Quando os alunos buscam uma síntese numa discussão sobre determinado fenômeno ou tema relacionado à ciência, estão buscando modelos explicativos mais abrangentes, o que passa necessariamente pela elaboração de argumentos mais completos.

\section{Tabela 1 - Categorias desenvolvidas por Driver e Newton (1997) para a análise da argumentação dos alunos a partir do modelo de argumento de Toulmin}

\begin{tabular}{|l|c|}
\hline Tipo de Argumento & Nível \\
\hline Afirmação isolada sem justificativa & 0 \\
\hline Afirmações competindo sem justificativas & 0 \\
\hline Afirmação isolada com justificativa & 1 \\
\hline Afirmações competindo com justificativas & 2 \\
\hline Afirmações competindo com justificativas e qualificadores & 3 \\
\hline Afirmações competindo com justificativas respondendo por refutação & 3 \\
\hline Fazer julgamento integrando diferentes argumentos & 4 \\
\hline
\end{tabular}

Uma dimensão do modelo de Toulmin é desconsiderada nesta classificação; as justificativas empregadas pelos alunos não são hierarquizadas em hipotéticas ou conhecimentos básicos, qualquer tipo de garantia apresentada para sustentar uma afirmação é válido.

\subsection{Proposta de análise das interações discursivas}

De acordo com Lotman (1988 apud Mortimer e Machado, 1997) um texto, escrito ou falado, pode ter duas funções: transmitir significados ou gerar novos. A função de transmissão implica na existência de um código comum entre transmissor e receptor, qualquer diferença de interpretação pode resultar numa falha no sistema de comunicação. No contexto escolar esta função é muito comum, há vários momentos em que o professor faz explanações, porém também pode ocorrer em alguns diálogos. Um padrão discursivo muito comum na sala de aula é o IRF (Edward e Mercer, 1987 apud Mortimer e Machado 1997) - o professor inicia o diálogo $(\mathrm{I})$, os alunos respondem $(\mathrm{R})$ e o primeiro dá um feedback (F). Quando o professor faz perguntas aos alunos exigindo fidelidade a significados já compartilhados pela classe, ou seja, perguntas com respostas bem definidas, este padrão é denominado avaliativo.

A função de transmissão ou de reforço de um texto também pode ser associada a um "discurso de autoridade", dentro da teoria da enunciação de Bakhtin (1993). Segundo o autor, 
apesar de toda enunciação apresentar uma intertextualidade, caracterizada pelas diversas significações (plurilingüismos) já atribuídas, através de outras enunciações, a seu tema, num "discurso de autoridade" somente a voz do locutor aparece explicitamente. Neste caso, assim como no padrão IRF avaliativo, é exigida uma fidelidade aos significados apresentados pelo locutor, sendo proibida a apropriação livre das palavras.

Quando a função do texto é a geração de novos significados, a diversidade de interpretações para o tema em questão é bem vinda. O dialogismo entre locutor e interlocutor, assim como entre o locutor e os diversos significados já atribuídos ao tema de sua enunciação é explícito. A participação ativa dos interlocutores é valorizada pelo locutor, deixando transparecer em sua fala múltiplas vozes. Isto pode ser identificado, por exemplo, quando o locutor utiliza-se de algum significado ou modo de articular idéias já utilizado pelo interlocutor para enriquecer seu enunciado. Este tipo de enunciado é denominado por Bakhtin como "internamente persuasivo", já que coloca um grande peso na voz do ouvinte. O padrão IRF num texto visando a geração de novos significados é elicitativo, ou seja, o professor inicia o diálogo, o aluno responde e, ao invés de avaliar a resposta do aluno, o professor procura estimulá-lo a acrescentar novas idéias à discussão, o que pode ser feito através de uma nova pergunta.

Mortimer e Machado identificaram na fala do professor uma alternância entre um "discurso persuasivo" e um "discurso de autoridade" durante uma aula visando mudança conceitual. Esta alternância mostrou-se importante para auxiliar os alunos na identificação e superação de conflitos cognitivos. Nossa intenção no presente trabalho é experimentar esta classificação em nossas observações. Para tanto, procuramos identificar em primeiro lugar os padrões discursivos IRF e, a partir daí, classificá-los dentro de uma tendência avaliativa ou elicitativa, de acordo com a exigência ou não de fidelidade pelo professor.

\section{Aspectos Metodológicos}

O presente trabalho tem como problema de pesquisa a análise das interações discursivas em aulas de Física envolvendo discussões significativas para a aprendizagem dos alunos, visando esclarecer dois aspectos: como estes argumentam e qual o papel do professor em estimular essa argumentação. Para tanto, optamos por analisar dados já coletados em outra pesquisa (Silva, 1995), que apresenta transcrições de discussões que mostraram-se importantes, segundo o autor, para a construção de idéias sobre conceitos de Calor e Temperatura por parte dos alunos. Desta forma, pudemos investigar a argumentação enquanto um meio de favorecimento da aprendizagem, acrescentando um novo olhar para a compreensão de aspectos envolvidos numa experiência bem sucedida. É fundamental ressaltar que o contexto de realização da pesquisa citada foi considerado em nossa análise, assim como todas as informações sobre as condições de produção dos debates.

A referida tese apresenta transcrições amplas das discussões dos alunos, entre si e também com o professor, ao longo de uma seqüência de ensino voltada para o estudo do funcionamento de uma forno de microondas. As aulas transcritas foram realizadas com alunos do primeiro ano do Ensino Médio da Escola de Aplicação da FEUSP. A partir destas 
transcrições, selecionamos um episódio de ensino dividido em duas cenas, correspondendo, respectivamente, à segunda e à quarta aulas da seqüência.

\section{Análise de duas cenas de um episódio de ensino}

A seleção das cenas analisadas foi feita com base em nosso objetivo de pesquisa. A cena 1, na maior parte do tempo, apresenta a argumentação dos alunos na ausência do professor, enquanto a cena 2, conta com sua presença, permitindo, assim, além da análise dos argumentos dos alunos, o acompanhamento dos padrões discursivos estabelecidos a partir das intervenções do professor.

A seguir é apresentada a análise das duas cenas selecionadas. Ao lado da transcrição das falas dos alunos foi acrescentada uma coluna, onde são indicados componentes identificados nos argumentos dos alunos e também padrões discursivos identificados na presença do professor.

\section{CENA 1A - TENTANDO EXPLICAR O FUNCIONAMENTO DO FORNO DE MICROONDAS}

Esta cena corresponde a parte de uma discussão de um grupo de alunos para buscar um consenso entre respostas dadas individualmente pelos membros do grupo a questões apresentadas na aula anterior. As questões em discussão são:

1. relacione abaixo os aparelhos e/ou dispositivos que podem ser usados em uma casa, destinados a provocar aquecimento.

2. Agrupe-os e explique como eles funcionam.

1. E: [falando com o aluno F] Passa a limpo ... você .... pra entregar

2. J: A gente coloca ... da radiação ... como a gente faz? É irradiação ou radiação?

Hipótese 1

3. E: Eu acho que é $i$

4. F: Vou procurar no dicionário ... [pega na sua mala um dicionário em edição de bolso]

5. J: O que está escrito em irradiação?

6. F: "ato ou efeito de irradiar, bombardeio de uma substância por Conhecimento básico um feixe de partículas"

7. J: Mas ... até aí ...

8. E: Então vê radiação ...

[F procura novamente no dicionário]

9. J: O que vocês acham que é?

10. E: Eu acho que é ... tipo luz

11. J: Como assim, ele provoca luz? ... mas o aquecimento, o calor Hipótese 2: tipo de luz ... de onde vem o calor? Da luz?

12. E: Do feixe de luz 
13. J: Será ... assim? Eu não sei ...

14. E: Eu acho que também deve ser um tipo de filamento

15. F: Achei ... "radiar: emitir ondas e energia calorífica, luminosa, etc. Cintilar, resplandecer".

Hipótese 3:

complementa a hip. 2

Conhecimento básico

Justificativa para

hipótese 2

Retoma hipótese 3

19. J: Sabe porque eu não acho que é filamento, senão seria resistível e não radiação ...

20. F: $\dot{E}$...

21. E: Então é algum tipo de luz ...

22. J: A luz é emitida mas ... acho que não é a luz que aquece ... quando se põe algo no sol ... tipo tudo aquece ... o prato também.

23. A: Eu também acho que não ... o que deve ter dentro do ... forno para soltar as ...

24. F: Eu tô procurando microondas [no dicionário]

25. J: Acho que não é importante .... vamos tentar a gente ...
Retoma a hipótese 2

Refutação da

hipótese 3

Apoio à refutação

Refutação da

hipótese 2

Apoio à refutação

Na seqüência acima os alunos estão preparando um material escrito para ser entregue ao professor e apresentam uma grande preocupação com o significado das palavras empregadas, buscando legitimar suas afirmações através de conhecimentos básicos usando o dicionário. Duas hipóteses complementares sobre o princípio de funcionamento do microondas surgem na discussão (falas 10 e 14): a luz gera calor e esta deve ser gerada por algum filamento.

A refutação ao filamento (fala 19) é baseada num questionamento da nomenclatura para classificar os aparelhos e não em algum dado empírico ou teoria. Já a refutação à hipótese da luz como princípio de funcionamento (fala 22) é mais elaborada, contando com a apresentação de uma situação em que esta não é válida.

26. E: Vamos começar ...

27. J: Eu vou ler de novo ... o que diz sobre radiação pra gente pensar o que é .... é o aquecimento através de ondas, não é? Por isso é que chama microondas ... a luz eu sei que tem a luz ... a onda é aquela tal ... mas ... quando a gente colocar um prato não aquece por igual ... as vezes uma parte fica fria e a outra ... $\quad$ Hipótese 1 
28. F: As ondas são irregulares ...

29. J: É? ... As ondas têm irregularidades?

30. E: Chama o professor ... mostra pra ele ...

31. J: Professor tá difícil ... essa coisa de microondas ...

32. Pr: Deixa eu ver ... ajudar na discussão ... Eu quero cozinhar uma carne, por exemplo, pra isso eu posso dispor do fogão ... a IRF avaliativo combustível ... a gás e de um forno de microondas ... a primeira coisa ... é o tempo de cozimento eles são iguais?

33. J: Não ... o microondas a gente pode controlar a intensidade e o tempo ...

34. Pr: Ótimo ... o microondas doura as coisas?

35. [todos falam juntos]

36. Pr: Pera aí ... um por vez...

37. F: Não ... porque ele cozinha por dentro ...

Hipótese 2

38. Pr: Ótimo vocês já tão começando a levantar hipóteses de que um processo diferente tá ocorrendo ...

39. E: Aqui a gente tinha feito ... que ele aquece substâncias que tinham $50 \%$ de água ...

40. Pr: Por que $50 \%$ de água?

41. E: Não só $50 \%$ de água ... $50 \%$ ou mais ... e que o prato não aquece por que ... não absorve as ondas ...

42. J: Eu não entendo esse negócio ... de ondas ... ainda não entrou

Afirmação com na minha cabeça.

43. Pr: Tá bom então coloque uma interrogação nisto ...

44. E: Põe aí, o microondas só cozinha por dentro ...

45. J: E não doura ...

46. E: Tipo frango fica branco ...

No trecho acima os alunos continuam buscando uma explicação para o princípio de funcionamento do microondas e uma nova hipótese é levantada no turno 29: as ondas são irregulares. Porém não há uma continuidade nesta afirmação já que os alunos parecem não ter conhecimentos suficientes para questioná-la.

No turno 32, pela primeira vez, o professor entra na discussão e sua atitude é de promover novas questões, tentando ajudar os alunos a reorganizarem suas idéias. O padrão do discurso do professor é avaliativo, considerando que suas perguntas diretivas. Mesmo quando o professor elogia apenas a formulação de uma hipótese, sem se referir a sua validade ou não (turno 37), os alunos compreendem tal atitude como uma avaliação de que aquela seria a resposta correta. Isto é notado na fala 44 quando incluem esta informação numa lista de dados.

Apesar de não chegarem a nenhuma conclusão, os alunos foram evoluindo ao longo da discussão elaborando diferentes hipóteses e apresentando dados a favor e contra as mesmas. A presença de refutações mostrou uma preocupação com o rigor no uso do vocabulário, assim 
como a capacidade de associar evidências com as hipóteses desenvolvidas. O discurso avaliativo do professor ajudou os alunos a acrescentarem novos dados ao problema. O nível das argumentações na cena todo foi 3 , de acordo com a constante busca de justificativas para apoiar ou negar as explicações elaboradas.

Cena 1B - Comparando o funcionamento dos fornos convencional e de microondas

Esta cena ocorreu duas aulas depois do $1 \mathrm{~A}$. Nesta aula, antes da seqüência analisada, o professor havia feito algumas experiências com os alunos em laboratório, comparando o forno de microondas com o forno elétrico convencional. A seguir apresentamos a transcrição da fase da aula em que o professor pediu aos alunos que lessem em voz alta o que haviam escrito sobre cada classe de aquecedores a partir das discussões das aulas anteriores.

1. Pr: Vamos lá ... o que acontece no microondas? Leia as suas conclusões ...

2. J: [ o aluno não lê e sim explica sem olhar para o papel] Eu não sei direito ... mas eu li que o atrito das partículas das microondas produz calor e esse vai se propagando ... fazendo muita agitação no alimento. Elas fazem com que as partículas ... do alimento vai se agitando e assim aquecendo.

3. Pr: Você chegou a ler? A que conclusão vocês chegaram?

4. J: Que as microondas estão ... ou fazem uma grande agitação e ... elas passam essa ... agitação para o alimento nas várias formas e com essa agitação o alimento se aqueça ... fique com a temperatura maior ...

5. F: Aí vai aquecendo a superfície ...

6. J: Aquecendo ... agitando ... a superfície e passando através das partículas do alimento para todas as outras ... entrando para o centro do alimento ...

7. Pr: Esse processo é o cozimento?

8. J: É ... constantemente ... as ondas estão dando agitação para as partículas da superfície dos alimentos ... estas vão dar para as mais de dentro e estas para as mais de dentro até ficar cozido.

9. Pr: Explica melhor ... o microondas produz as ondas e quem irá sentir essas ondas? Quem irá interagir com as ondas do forno?

10. J: A água ... acho que a água ...

11. Aluno 8: Professor ... eu coloquei parecido com o $J$... eu coloquei que as ondas interagem diretamente com o alimento ... não interagem com o recipiente ou com o ar ... que tá lá dentro ... então essa energia de agitação das moléculas do alimento vai ser maior ... que a energia ... das moléculas do ar que tá no forno normal [a gás] ... então tem mais diferença de temperatura
Padrão IRF elicitativo

Duas idéias são

apresentadas: atrito

produz calor e

agitação provoca

aquecimento.

Complementa a fala

anterior relacionando

agitação e

temperatura

Complementa a fala

anterior

Utiliza a afirmação

anterior de forma

contrária: o

aquecimento ocorre

de fora para dentro

\section{Hipótese}

Dado justificando a

diferença entre as

temperaturas nos

fornos de microondas 
... vai ter e mais propagação de calor ... então vai evaporar mais água também e vai ficar mais seco.

12. Pr: Pera aí ... O aluno 8 colocou uma nova situação: ele falou de moléculas de alimentos ... quem são as moléculas que basicamente constituem um alimento?

13. Aluno 9: Água ...

14. Pr: Água e que mais? Alimento é constituído de que?

15. Aluno 10: Amido ... carboidratos ... e outras coisas.

16. Pr: Será que as microondas interagem como um todo? ... em todas as moléculas? Será que elas interagem com todas?

17. Aluno 5: Acho que são com as da água, né?

18. J: É aí as moléculas de água passam para as outras moléculas do alimento.

19. Pr: Ótimo! Conta pra mim João, a que temperatura a água começa a evaporar? A que temperatura ela vai entrar em ebulição?

20. J: 100 graus ...

21. Pr: 100 graus Celsius ... agora eu pergunto o seguinte: será que essa microonda vai interagir com uma molécula de proteína?

22. J: As moléculas de água ...

23. Pr: $O$ aluno 8 falou outra coisa importante: que a temperatura que o alimento foi submetido no microondas é maior que a do que foi submetido no forno a gás. Vocês concordam?

24. Aluno 11: Eu discordo ...

25. Pr: Diga ...

26. Aluno 11: Se a molécula de água evapora a 100 graus, 0 máximo que ela vai ficar é até 100 graus Celsius ... no microondas. Depois ela vai evaporar ... e no forno tem uma temperatura maior porque ele aquece todas as moléculas ... não só as de água ... A gente quando abre um microondas vê um monte de vapor ... e no forno sente um bafo ... um ar quente ...

27. Pr: O forno que você falou chega a que temperatura ... que você vê escrito no botão?

28. Aluno 12: No meu forno tá escrito baixo, médio ...

29. Pr: Tá legal ...

30. Aluno 11: É 250, 300 graus Celsius ...

31. Pr: É dá pra notar que no forno a gás a temperatura interna é muito maior, porque ele funciona, como vocês disseram, aquecendo tudo e no microondas só a água ... para aquecer o resto. Agora só falta ... um instante pessoal ... quem ficou de ver e convencional

Conclusão

Padrão IRF avaliativo

Hipótese

Apoia e complementa a fala anterior

Padrão IRF avaliativo

Padrão IRF elicitativo

Afirmação com

justificativa utilizando

conhecimento básico

Refutação da fala 11

Dado 
como funciona os fornos de microondas que também douram os alimentos?

Padrão IRF avaliativo

32. Aluno 13: Eu ... tá ... li no catalogo que ele tem uma resistência dentro que após ... cozinhar é ligada para aquecer ...

33. Pr: Esse forno então é um tipo misto que funciona como microondas e depois como forno elétrico ... tudo bem?

Até o turno 12 o discurso do professor foi elicitativo. O aluno $\mathrm{J}$ apresentou sua explicação levantando algumas idéias sobre o aquecimento no microondas; relacionou atrito e aquecimento, bem como, agitação com temperatura. No turno 11 , 0 aluno 8 fala espontaneamente, sem ser solicitado, o que lembra as principais formas de argumentação nas aulas de ciências levantadas por Candela (1997). Este aluno acrescenta à discussão a diferença entre o forno de microondas e o convencional. O professor aproveita esta fala para retomar o papel da água no aquecimento e seu discurso muda de padrão, tornando-se avaliativo

Esta alternância de padrões discursivos ajuda os alunos a incorporarem gradativamente novos aspectos do problema em suas falas. Se por um lado eles apresentam livremente suas idéias, por outro o professor chama atenção para pequenos detalhes quando necessário. Enquanto no turno 8 o aluno $\mathrm{J}$ falava da propagação da agitação das partículas da superfície para o interior do alimento, no turno 17 este mesmo aluno já especifica uma transmissão dessa agitação das moléculas de água para outras moléculas do alimento.

O padrão do discurso do professor continua a ser avaliativo até o turno 23. Através de um discurso elicitativo, o professor também procura chamar a atenção dos alunos para o que seus colegas falam (turno 23). Uma oposição aparece no turno 24, cuja justificativa é apresentada na fala 26. O aluno 11 apresenta um argumento completo sobre a diferença entre os fornos elétrico e microondas, baseado no conhecimento básico requisitado pelo professor no turno 19 (durante um padrão avaliativo). Este aluno, ao refutar a fala do colega (turno 11), acaba apresentando uma síntese de tudo que foi discutido sobre a diferença de temperatura entre os dois fornos. De acordo com o que já havia sido colocado pelos alunos A5 e J itens 17 e 18 e considerando o conhecimento básico sobre a temperatura de ebulição da água, A11 diferencia os dois tipos de fornos. O nível das argumentações na escala de Driver e Newton é 4.

No final, o professor sistematiza as idéias levantadas pelos alunos, estabelecendo uma explicação que, daí em diante, passa a ser um conhecimento básico já compartilhado pelo grupo, o que caracteriza um discurso avaliativo.

\section{Conclusões}

O presente trabalho apresenta duas perspectivas de análise da argumentação em sala de aula, uma voltada para o acompanhamento dos argumentos construídos pelos alunos e outra para a observação das posturas adotadas pelo professor ao longo das discussões. As cenas analisadas podem ser divididas em três diferentes fases de acordo com a participação do 
professor nas discussões. Na cena $1 \mathrm{~A}$, até o turno 25, o professor não esteve presente, enquanto nos itens restantes predominou o padrão discursivo avaliativo. Já na cena $1 \mathrm{~B}$, houve uma alternância entre os padrões avaliativo e elicitativo.

$\mathrm{Na}$ ausência do professor, o nível de argumentação dos alunos foi bastante elevado, contando com duas refutações. Nesta fase os alunos apresentaram grande preocupação em associar dados do cotidiano e conhecimentos básicos às suas afirmações. A identificação de elementos constituintes de argumentos individuais, através do padrão de Toulmin (1958), mostrou-se necessária e importante para o acompanhamento do processo de construção das explicações coletivas. O emprego isolado das categorias de Driver e Newton (1997) não permitiria a diferenciação entre os tipos de justificativas empregadas pelos alunos em suas falas isoladas. A partir de tais categorias todas afirmações com justificativa teriam o mesmo peso na classificação dos argumentos, não havendo diferenças entre uma justificativa baseada no senso comum e aquela baseada em conhecimentos adquiridos ao longo da escolarização.

Quando o professor começou a participar da discussão através de um padrão avaliativo, idéias novas foram acrescentadas ao problema em questão, porém nenhuma conclusão foi obtida. Já na cena 1B, foi observado que a alternância entre os padrões elicitativo e avaliativo ajudou os alunos a apresentarem suas idéias e recordarem conhecimentos básicos relacionados ao assunto. Isto impulsionou a construção de uma explicação para o fenômeno em discussão, fundamentada nas teorias já estudadas anteriormente. Assim, enquanto o padrão elicitativo estimulou as discussões, a presença do avaliativo contribuiu para manter a atenção dos alunos nos temas já estudados ou em aspectos mais relevantes dentro dos objetivos das mesmas. Da mesma forma, o aproveitamento da fala espontânea do aluno 8 enriqueceu substancialmente a discussão.

A identificação, através da análise das interações discursivas, das diferentes posturas que costumam ser assumidas pelos professores em sala de aula possibilita a compreensão dos papéis que estas podem representar nas diferentes facetas do ensino, contribuindo para seu aperfeiçoamento. Neste trabalho, assim como em Candela (2000), o padrão IRF, embora muitas vezes criticado pela falta de espaço que oferece para a participação livre dos alunos e para a criação de ambientes de discussão, possibilitou a elaboração de argumentos de qualidade por parte dos mesmos. A classificação de tal padrão dentro das tendências elicitativa ou avaliativa, contribuiu para a compreensão do sucesso em sua utilização.

\section{Referências}

Bakhtin, M., 1997. Estética da Criação Verbal. São Paulo, Martins Fontes. (originalmente produzida em 1979)

Bakhtin, M., 1993. Questões de Literatura e de Estética, São Paulo, UNESP.

Candela, A., 2000. Co - Production of School Knowledge in Subjugated Contexts. III Conferência de Pesquisa Sócio - cultural. Campinas.

Candela, A., 1997. El Discurso Argumentativo de la Ciencia en el Aula. Encontro sobre Teoria e Pesquisa em Ensino de Ciências, Belo Horizonte. 
Cobern, W. W. e Aikenhead, G. S., 1998. Cultural Aspects of Learning Science. In: International Handbook of Science Education. Klower Academic Publishes. Editores: Fraser, B. J. e Tobin, K. G.

Driver, R.; Newton, P., 1997. Establishing the norms of scientific argumentation in classrooms. Paper prepared for presentation at the ESERA Conference, 2 - 6 September, 1997, Rome.

Duit, R.; Treagust, D. F., 1998. Learning in Science - From Behaviourism Towards Social Construtivism and Beyond. In: International Handbook of Science Education. Klower Academic Publishes. Editores: Fraser, B. J. e Tobin, K. G.

Jiménez Aleixandre, M. P; Reigosa Castro, C.; Álvarez Pérez, V., 1998. Argumentación en el Laboratorio de Física. Trabalho apresentado no VI Encontro de Pesquisa em Ensino de Física, 26 a 30 de outubro, Florianópolis.

Lotman, Y. M., 1988. The semiotics of culture and the context of a text. Soviet psychology, 26, $32-51$.

Mortimer, E. F. e Machado, A. H., 1997. Múltiplos olhares sobre um episódio de ensino: "Por que o gelo flutua na água?". Encontro sobre Teoria e Pesquisa em Ensino de Ciências, Belo Horizonte.

Richmond, G.; Striley, J. 1996. Making meaning in classrooms: Social processes in small group discourse and scientific knowledge building. Journal of Research in Science Teaching 33 (8), 839 - 858

Scott, P. 1997. Teaching and learning Science concepts in tha classroom: talking a path from spontaneous to scientific knowledge. Encontro sobre Teoria e Pesquisa em Ensino de Ciências, Belo Horizonte.

Silva, D., 1995. Estudo das Trajetórias Cognitivas de Alunos no Ensino da Diferenciação dos Conceitos de Calor e Temperatura. Tese de Doutorado apresentada ao Instituto de Física e à Faculdade de Educação da Universidade de São Paulo, São Paulo.

Sutton, C., 1998. New Perspectives on Language in Science. In: International Handbook of Science Education. Klower Academic Publishes. Editores: Fraser, B. e Tobin, K. G.

Toulmin, S. 1958. The uses of argument. Cambridge University Press. 